\title{
Detection of trace nickel in environmental water by high-performance liquid chromatography after dispersive liquid-liquid microextraction
}

\author{
Fang Chen and Song Liu* \\ Foshan City Water Industry Group Company, LTD, Foshan 528000, China \\ gdgdls@tom.com
}

\begin{abstract}
Keywords: Nickel; high-performance liquid chromatography; dispersive liquid-liquid microextraction. Abstract. Because of the toxic effects of nickel on human health and ecosystem, it is necessary to detect trace nickel in aquatic environments. A new method was proposed for the detection of trace nickel in water, by high performance liquid chromatography with diode array detection (HPLC-DAD) after dispersive liquid-liquid microextraction (DLLME). Dithizone was used as the chelating agent for $\mathrm{Ni}(\mathrm{II})$. Several factors influencing the extraction efficiency were studied, and the optimum experimental conditions were achieved. The analytical performance of the method was examined, and it was found that the limit of detection (LOD) was $0.12 \mu \mathrm{g} / \mathrm{L}$ and the RSD was $5.3 \%$. The proposed method was utilized in the determination of nickel in environmental water samples with recoveries of 95.6-106.0\%.
\end{abstract}

\section{Introduction}

Nowadays there is a growing public concern over the potential risk of heavy metals [1-3]. Nickel can cause serious health problems such as nasopharynx, lung and dermatological diseases and malignant tumors [4]. Therefore, it is essential to establish suitable techniques for the analysis of nickel in various environmental matrices. Inductively coupled plasma mass spectrometry, inductively coupled plasma optical emission spectrometry can conduct sensitive detection of heavy metals [5-8]. However, the costs of these methods are high.

Because nickel in environmental water samples is often at low concentrations, suitable sample preparation procedures are usually required before its instrumental determination. Among various sample preparation techniques for metal ion and organic pollutants, solid phase extraction is the most often used one [9-17]. Recently, dispersive liquid-liquid microextraction (DLLME) as a simple, fast, sensitive, low-cost and solvent-less microextraction technique has been developed [18-21].

In this work, we propose a new method for detection of trace $\mathrm{Ni}(\mathrm{II})$ in water samples, using a combination of DLLME with HPLC-DAD. Dithizone (DZ) was employed as the chelating agent for $\mathrm{Ni}(\mathrm{II})$. The experimental conditions were studied and optimized. Finally, the proposed method was used for the detection of $\mathrm{Ni}(\mathrm{II})$ in environmental water samples.

\section{Materials and methods}

\section{Reagents}

The stock standard solution of Ni(II) (1000 mg/ L) was supplied by National Iron and Steel Material Test Center, China. Dithizone was obtained from Tianjin Damao Chemical Reagent Factory (Tianjin, China). Hydrochloric acid and nitric acid were of ultra purity grade, other reagents were of analytical reagent grade.

\section{Apparatus}

The separation and analysis were conducted on a HPLC system (SHIMADZU, Kyoto, Japan) equipped with diode-array detection (DAD, SPD-M20A). A Shim-pack VP-ODS column $(150 \times 4.6$ mm I.D.) was used. The detection wavelength was $254 \mathrm{~nm}$.

\section{Dispersive liquid-liquid microextraction procedures}

A mixture of $40 \mu \mathrm{L}$ of chlorobenzene (extraction solvent) and $0.5 \mathrm{~mL}$ of methanol (disperser solvent) was quickly injected into a water sample solution. After $3 \mathrm{~min}$, a cloudy solution was formed. 
Then it was centrifuged. The extractant was sedimented at the bottom of centrifuge tube. Afterwards, $20 \mu \mathrm{L}$ of which was injected into the HPLC system for detection.

\section{Results and discussion}

\section{Effect of sample pH}

Sample $\mathrm{pH}$ is generally one of the most critical parameters for complex formation. Fig.1 shows the dependence of extraction recovery of $\mathrm{Ni}$ (II) as $\mathrm{Ni}(\mathrm{II})$-DZ chelate on sample $\mathrm{pH}$ value. It is obvious that this effect was significant. The recovery increased with the increase of $\mathrm{pH}$ from 5 to 9 , and then decreased when the $\mathrm{pH}$ value was larger than 10 . Lower extraction recoveries of $\mathrm{Ni}(\mathrm{II})$ at low $\mathrm{pHs}$ were resulted from the competition of $\mathrm{H}^{+}$with $\mathrm{Ni}(\mathrm{II})$ for reaction with $\mathrm{DZ}$. Thus, $\mathrm{pH} 9$ was chosen.

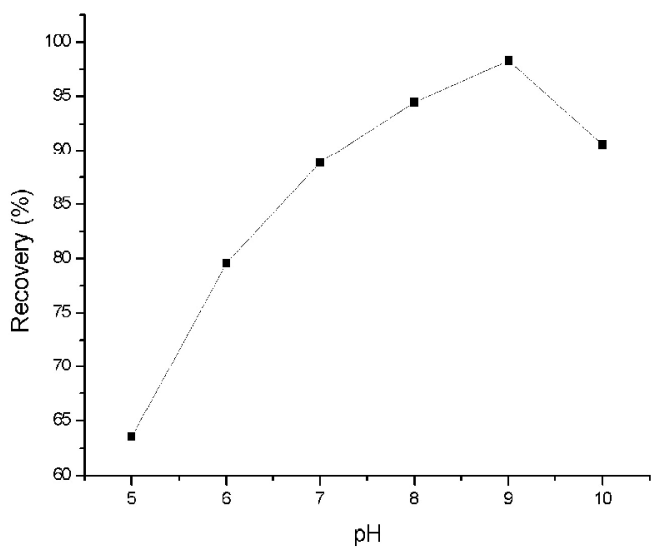

Fig.1 Effect of $\mathrm{pH}$.

\section{Effect of chelating agent concentration}

The effect of dithizone concentration on the preconcentration efficiency for $\mathrm{Ni}(\mathrm{II})$ was examined in a range from 0.0002 to $0.001 \%(\mathrm{w} / \mathrm{v})$, and the results showed that the extraction recovery for $\mathrm{Ni}(\mathrm{II})$ enhanced with the increase of dithizone concentration from 0.0002 to $0.0006 \%$, and then kept almost unchanged up to $0.001 \%$. Based on these results, $0.0006 \%(\mathrm{w} / \mathrm{v})$ was adopted as the suitable DZ concentration for chelating reaction.

\section{Effect of type and volume of extraction solvent}

In this work, three organic solvents were evaluated as the extraction solvents, including tetrachloroethane, carbon tetrachloride and chlorobenzene. It was found that chlorobenzene gave the highest peak area for $\mathrm{Ni}$ (II)-DZ chelate, and was thus selected as the most suitable extraction solvent. To examine the effect of extraction solvent volume on the extraction efficiency, the volume of chlorobenzene was adjusted in the range of 20-60 $\mu \mathrm{L}$. As shown in Fig.2, the extraction efficiency increased with increasing the volume of chlorobenzene from 20 to $40 \mu \mathrm{L}$. However, the extraction efficiency decreased when the volume was larger than $40 \mu \mathrm{L}$. Thus, $40 \mu \mathrm{L}$ was the optimal extraction solvent volume. 


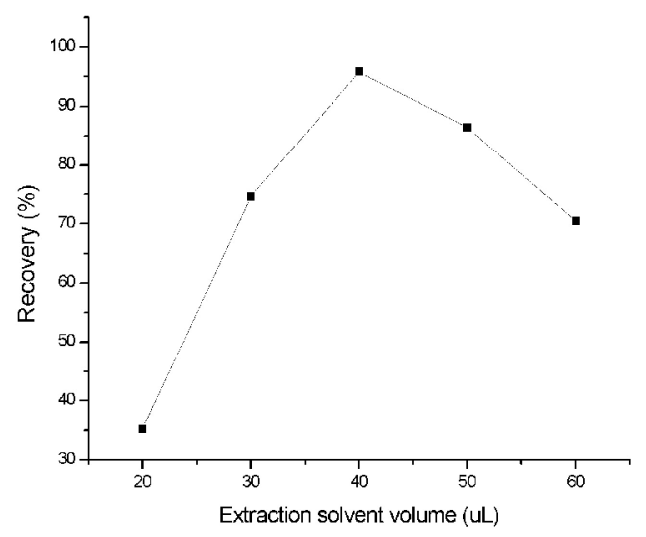

Fig.2 Effect of extraction solvent volume.

\section{Effect of type and volume of disperser solvent}

To select a suitable dispersive solvent, methanol, acetonitrile and acetone were tested as the dispersive solvents. It was found that the highest extraction recovery of $\mathrm{Ni}$ (II) was obtained when using methanol. Thus, methanol was chosen as the eluent for DLLME. To examine the effect of methanol volume on the extraction recovery of $\mathrm{Ni}(\mathrm{II})$, different volumes of methanol $(0.1,0.3,0.5,0.7$ and $1.0 \mathrm{~mL}$ )were tested. The results indicated that the recovery increased with the enhancement of methanol volume up to $0.5 \mathrm{~mL}$ and then decreased with further enhancement of methanol volume. Therefore, $0.5 \mathrm{~mL}$ of methanol was selected for the following experiments.

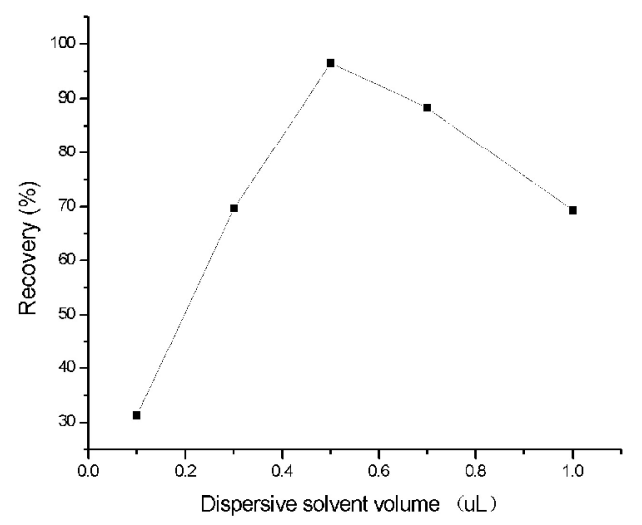

Fig.3 Effect of dispersive solvent volume.

\section{Analytical performance}

Under the determined optimum conditions, the analytical performance of the developed detection method was examined. It was found that in a $\mathrm{Ni}(\mathrm{II})$ concentration range of $1-50 \mu \mathrm{g} / \mathrm{L}$, good linear correlation coefficient could be obtained $\left(\mathrm{R}^{2}=0.9935\right)$. The limit of detection (LOD) were $0.12 \mu \mathrm{g} / \mathrm{L}$ The relative standard deviation (RSD) for six replicate measurements of $5.0 \mu \mathrm{g} / \mathrm{L} \mathrm{Ni}(\mathrm{II})$ was $5.3 \%$.

\section{Environmental water analysis}

The developed method was used to the detection of trace am Ni(II) ions in four environmental water samples, and the analytical results were given in Table 1. As can be seen, the recoveries for the spiked samples were between $95.6 \%$ and $106.0 \%$, and the RSD for Ni(II) concentration in the environmental samples ranged from 3.8 to $6.2 \%$. 
Table 1 Analytical results of Ni(II) in environmental water samples.

\begin{tabular}{lcccc}
\hline Sample & Ni add $/(\mu \mathrm{g} / \mathrm{L})$ & Ni found $/(\mu \mathrm{g} / \mathrm{L})$ & Recovery $(\%)$ & RSD $(\%)$ \\
\hline River water & 0 & 51.6 & --- & 4.7 \\
& 50.0 & 99.4 & 95.6 & 3.8 \\
Lake water & 0 & 23.6 & --- & 4.9 \\
& 20.0 & 42.9 & 96.5 & 4.1 \\
Pond water & 0 & 14.4 & --- & 6.2 \\
& 10.0 & 25.0 & 106.0 & 5.3 \\
Well water & 0 & 40.5 & --- & 4.0 \\
& 50.0 & 92.3 & 103.6 & 4.5 \\
\hline
\end{tabular}

\section{Conclusions}

This work presented a new method, DLLME coupled with HPLC-DAD, for detection of trace nickel in aqueous solution. The proposed method has some advantages such as high sensitivity and precision, and fast and easy operation. The method was applied to the extraction and detection of $\mathrm{Ni}(\mathrm{II})$ ions in environmental water samples, and satisfactory results were obtained.

\section{References}

[1] Baykov B.D., Stoyanov M.P. and Gugova M.L. 1996, Toxicol. Environ. Chem. 54: 155159.

[2] Zou J., Ma X., Dang Y. and Chen Y. J. Anal. At. Spectrom. 2014, 29(9): 1692-1697.

[3] Huang R., Ma X., Li X., et al. J. Colloid Interf. Sci. 2018, 514 :544-553.

[4] Korn M.G.A., Morte E.S.B., dos Santos D.C.M.B., et al. Appl. Spectrosc. Rev., 43, 67-92.

[5] Ma X. and Zhang Z. Anal. Chim. Acta. 2003, 485(2): 233-239.

[6] Ma X. and Zhang Z. J. Anal. At. Spectrom. 2004, 19(6), 738-742.

[7] Poitrasson F. and Freydier R. Chem Geology. 2005, 222(1-2): 132-147.

[8] Shih T. T., Hsieh C. C., Luo Y. T., et al. Anal. Chim. Acta. 2016, 916: 24-32.

[9] Chen J., Ma X. and Wu Y. Food Anal. Methods. 2014, 7(5): 1083-1089.

[10] Ma X., Huang P. and Chen M. Rare Metals. 2007, 26(6):541-546.

[11] Barbosa AF, Segatelli MG, Pereira AC, et al. Talanta. 2007, 71:1512-1519.

[12] Li C., Ma X., Zhang X., et al. J. Sep. Sci. 2017, 40(7): 1621-1628.

[13] Nong Y., Ma X., Fan S. and Yu Y. Anal. Methods. 2014, 6(12): 4124-4129.

[14] Chen Y., Ma X., Huang M., Peng, J., Li C. Anal. Methods. 2016, 8(4): 824-829.

[15] Heidari N.,Ghiasvand A. and Abdolhossaini S. Anal. Chim. Acta. 2017, 975:11-19.

[16] Li C., Ma X., Zhang X., et al.Anal. Bioanal. Chem. 2016, 408(27): 7857-7864.

[17] Zhang Y., Ma X. and Fan Y. Food Anal. Methods. 2014, 7(9): 1763-1769.

[18] Naseri M.T., Hemmatkhah P., Hosseini M.R.M., et al. J. Chromatogr. A. 2008, 610 :135-141.

[19] Gao Z. and Ma X. Anal. Chim. Acta. 2011, 702(1): 50-55.

[20] Afshar E A, Taher M A, Fazelirad H, et al. Anal. Bioanal. Chem. 2017, 409(7): 1837-1843.

[21] Li D., Ma X., Wang R., et al. Anal. Bioanal. Chem. 2017, 409(5): 1165-1172. 